\title{
AS INVESTIGAÇÕES FILOSÓFICAS ENQUANTO "ÁLBUM" CULTURAL
}

\author{
Ana Falcato \\ (Universidade Nova de Lisboa/ IFL)
}

\section{Duas interpretações para "Álbum”.}

No Prólogo das Investigações Filosóficas ${ }^{1}$, Wittgenstein afirma que o livro, e por razões que ultrapassam o seu famigerado estilo aforístico, não é mais do que um "álbum". A passagem do Prólogo em que esta ideia é identificada é a seguinte:

«Pontos iguais ou quase iguais eram renovadamente abordados a partir de novas e diferentes Direcções e novas imagens eram esboçadas. Algumas destas estavam mal desenhadas ou eram incaracterísticas, contendo todos os defeitos que afligem um desenhador fraco. E, uma vez estas retiradas, ficaram algumas aceitáveis que tiveram que ser ordenadas, por vezes cortadas, de forma a darem ao observador uma figura da paisagem. - Assim, este livro é apenas um Álbum». ${ }^{2}$

${ }^{1}$ Todas as citações das Investigações Filosóficas feitas ao longo deste trabalho serão extraídas de: WitTGENSTEIN, L., Philosophische Untersuchungen. Frankfurt am Main, Werkausgabe Band 1. As traduções do alemão são da minha inteira responsabilidade e, doravante, referir-se-á a obra através da sigla "IF". Veja-se também a tradução portuguesa de M.S.Lourenço: Tratado Logico-Filosófico/Investigações Filosóficas, Lisboa, Fundação Calouste Gulbenkian.

${ }^{2}$ In WittgensteIn, L., Philosophische Untersuchungen. Frankfurt am Main, Werkausgabe Band 1, "Vorwort", pp. 231-232: «Die gleichen Punkte, oder beinahe die gleichen, wurden stets von neuem von verschiedenen Richtungen her berührt und immer neue Bilder entworfen. Eine Unzahl dieser waren verzeichnet, oder uncharakteristisch, mit allen Mängeln eines schwachen Zeichners behaftet. Und wenn man diese ausschied, blieb eine Anzahl halbwegser übrig, die nun so angeordnet, oftmals beschnitten, werden mussten, dass sie dem Betrachter ein Bild der Landschaft geben konnten. - So ist also dieses Buch eigentlich nur ein Album».

Philosophica, 39, Lisboa, 2012, pp. 115-130 
A sugestão metafórica do Prólogo das IF foi muitas vezes explorada pelos comentadores enquanto definitória de uma técnica de análise conceptual, identificada e aplicada por Wittgenstein nas suas investigações filosóficas: a "representação panorâmica" [übersichtliche Darstellung] sobre as palavras na sua articulação proposicional e enquanto veículos expressivos. A disposição "perspectivística" das palavras seria, assim, um pouco como uma disposição fotográfica. Esta é uma interpretação possível para a metáfora do Prólogo; mas é apenas uma.

Num artigo de Stanley Cavell, intitulado "Declining Decline"3, que serviu de suporte à minha própria interpretação da ideia de "álbum" neste trabalho, é proposto um vínculo de tipo cultural entre os temas filosóficos tratados pelas IF e a relação de Wittgenstein com o seu tempo. A partir da síntese destas duas linhas de interpretação - uma mais "metodológica" ou descritiva de uma dada técnica de composição textual e outra mais comprometida com uma via de leitura e interpretação filosófica de um texto filosófico - poderemos forjar o sentido da expressão "álbum cultural". A proposta de Cavell parece-me, não apenas pouco comum como muito sugestiva porque, ao determinar o termo Cultura como uma "sinédoque para as formas de vida" 4 , oferece uma via de abordagem linguística e antropológica para a máxima wittgensteiniana de que «conceber uma linguagem é conceber uma forma de vida» (IF, §19).

Cavell propõe uma dupla interpretação para a expressão Forma de Vida: biológica e etnológica. Ambas estão intimamente vinculadas a uma matriz cultural, sendo a segunda interpretação extraída da obra de Spengler, Der Untergang des Abendlandes, na medida em que aproveita a reflexão deste sobre a própria ideia goethiana de "Morfologia" - que Spengler aplica a um estudo da formação das culturas e das civilizações.

Através da interpretação etnológica para "Forma de Vida", Cavell explora associativamente as referências de Wittgenstein a uma Umgangssprache ("an everyday language"), como o objecto da análise gramatical a aplicar a formas de linguagem correntes, incorporadoras de manifestações da cultura humana. Nesse âmbito, a análise de jogos descontínuos do registo linguístico habitual congrega uma descoberta da própria gramática cultural que lhes assiste.

Podemos atribuir às Investigações Filosóficas, não apenas a forma de reportagem fotográfica de um conjunto de "longas e enredadas viagens"5 (filosóficas) - um diagnóstico do próprio autor -, mas também

${ }^{3}$ CAVELL, S. "Declining Decline". In The Cavell Reader. Edited by Stephen Mulhall, Oxford, Blackwell Publishers, 1996, p. 352.

${ }^{4}$ A expressão é de Cavell.

${ }^{5}$ Esta é uma expressão utilizada por Wittgenstein no Prólogo das IF: «Die philosophischen Bemerkungen dieses Buches sind gleichsam eine Menge von Land- 
uma chave de composição temática e de leitura crítica dessa montagem fotográfica que obedece a um "transcendental cultural", sem o qual o próprio Álbum não teria a unidade de uma obra de filosofia cabal - por mais que a sua tutela fosse sempre a do segmento e nunca a do sistema.

\section{Um declínio da Cultura. Um declínio da linguagem?}

Ver-nos-emos forçados a analisar uma abordagem metafilosófica como a de S. Cavell às IF (na medida em que esta se constitui também como uma proposta de interpretação da estrutura textual das Investigações) a partir dos seus aspectos mais simples, sob pena de perdermos de vista as próprias IF como o seu objecto. A questão fundamental que aqui nos ocupa é a de saber se e até que ponto as IF e a via linguística de análise de um conjunto de problemas filosóficos a que Wittgenstein nelas se dedica poderão ser pensadas como actualizações reflexivas de um transcendental que é cultural.

A via que Cavell segue para demonstrar a validade desta perspectiva é devedora de uma ideia de Georg von Wright, num artigo de 1982 intitulado "Wittgenstein in relation to his times". ${ }^{6}$ Nesse artigo, o ex-aluno e um dos herdeiros do Nachlass, defende que entender a relação de Wittgenstein com o seu tempo é certamente um aspecto relevante de compreensão da sua perspectiva filosófica. Esta é, provavelmente, a tese nuclear do artigo de von Wright - e também do de Cavell, ainda que para o último essa consideração funcione mais como um substrato metodológico para outras ideias que quer ver desdobradas.

No artigo de von Wright podemos ler:

«Because of the interlocking of language and ways of life, a disorder in the former reflects disorder in the latter. If philosophical problems are symptomatic of language producing malignant outgrowths which obscure our thinking, then there must be a cancer in the Lebensweise, in the way of life $e^{7}$ itself».

Cavell, ao relacionar o entendimento spengleriano que o próprio von Wright tem de uma orgânica das formas de vida como a estrutura de configurabilidade linguística dos problemas filosóficos - conforme

schaftsskizzen, die auf diesen langen und verwickelten Fahrten entstanden sind». Philosophische Untersuchungen, "Vorwort". Frankfurt, Werkausgabe Band 1, p. 231.

${ }^{6}$ VON WRIGHT, G.H. "Wittgenstein in Relation to his times". Idem, Wittgenstein, Oxford, Basil Blackwell, 1982.

${ }^{7}$ O sublinhado é meu. 
entendidos por Wittgenstein - comenta que o termo "cancro" não se ajusta a este núcleo de semelhanças conceptuais. A actuação de uma enfermidade cancerígena sobre uma dada forma de vida implicaria - se o termo "cancro" não for arbitrariamente conotado com um sentido diferente do usualmente aceite - pensar na forma de vida como invadida por um corpo estranho e submetida a vias de tratamento que são, elas mesmas, externas e invasivas ao organismo doente; a própria extinção material do corpo afectado pelo cancro está associada a uma desintegração que pode ser violenta.

Porém, a ideia de Declínio [Untergang] civilizacional, no pensamento de Oswald Spengler, descreve uma morte natural, constitutiva da própria dinâmica histórica da cultura ocidental. Intuitivamente, basta que nos lembremos que um cancro - num corpo, numa forma de vida - está nos antípodas de uma morte natural (a sua representação está, inclusive, fora da extensão de uma noção realista de declínio).

$\mathrm{Na}$ Introdução a Der Untergang des Abendlandes, podemos ler:

«É bem sabido que todo o organismo tem o seu ritmo, a sua figura, a sua duração determinada [...] todos possuímos, com absoluta certeza, o sentimento de um limite, que é idêntico ao sentimento das formas orgânicas. Mas quando se trata da história das grandes formas humanas, domina um optimismo ilimitado com respeito ao futuro. [...] Ao invés da monótona imagem de uma história universal em linha recta, que apenas se mantém se fechamos os olhos aos factos, eu vejo fenómenos de múltiplas culturas poderosas; [...] cada uma dessas culturas imprime na sua matéria, que é o homem, a sua forma própria; cada uma tem a sua própria ideia; [...] a sua própria vida, o seu morrer próprio. [...] Não há uma "humanidade" velha. Cada cultura possui as suas próprias possibilidades de expressão ${ }^{8}$, que germinam, amadurecem, terminam e não renascem mais». ${ }^{9}$

${ }^{8}$ Meu sublinhado.

${ }^{9}$ SPENGLER, O. Der Untergang des Abendlandes. Erster Band: Gestalt und Wirklichkeit. München, Oskar Beck Verlag, 1920, pp.28-29: «Von jedem Organismus wissen wir, dass Tempo, Gestalt und Dauer seines Lebens[...] bestimmt sind. Hier hat jeder mit unbedingter Gewissheit das Gefühl einer Grenze, dass mit einem Gefühl für organische Formen identisch ist.Der Geschichte des höhern Menschentums gegenüber aber herrscht ein grenzenlos trivialer Optimismus in bezug auf die Zukunft.[...]Ich sehe statt des monotonen Bildes einer linienförmigen Weltgeschichte, dass man nur aufrecht erhält, wenn man vor der überwiegenden Zahl der Tatsachen das Auge schliesst, das Phänomen einer Vielzahl nächtiger Kulturen[...]von denen jede ihrem Stoff, dem Menschentum, ihre eigne Form aufprägt, von denen jede ihre eigne Idee[...] ihr eignes Leben, Wollen, Fühlen, ihren eignen Tod hat.[...]aber es gibt keine alternde "Menschheit". 
Wittgenstein menciona seis vezes Spengler nas Vermischte Bemerkungen, ainda que nas IF não lhe faça nenhuma referência directa, provavelmente porque a sua própria perspectiva já se tornara demasiado spengleriana, naquela que preparou para ser a obra que encenaria a sua "nova maneira de pensar".

A concepção das formas culturais como formas orgânicas, uma ideia que Spengler desenvolve a partir da noção de Natureza Viva [lebendige Natur] de Goethe pode não ter constituído uma via directa de inspiração para o conceito de formas de vida [Lebensformen] em Wittgenstein; mas, e para o ponto que aqui nos interessa, com toda a certeza que o foi a ideia spengleriana da Cultura como uma forma de natureza, isto é, não reduzida a um conjunto arbitrário de convenções arbitrárias.

Ora, se a Cultura é pensada como "uma forma de natureza" do humano, como podem - na economia do pensamento wittgensteiniano - as formas de linguagem (naturais), que só são possíveis se e porque a Cultura é o transcendental possibilitador da sua actualização, conflituar com os factos culturais ou, numa terminologia que ainda invoca o Tractatus, não respeitar uma forma lógica determinante, que é cultural? Não podem. Não porque estejam coarctadas na possibilidade de que isso acontecesse, mas porque a própria questão falha o seu suposto alvo. É uma pseudo-questão. Wittgenstein repete-o (dizemos que repete, porque já o afirmava no Tractatus, 5.5563) em IF §98:

«Por um lado é claro que cada proposição da nossa linguagem "está em ordem tal como está". Isto é, não aspiramos a um ideal, como se as nossas vagas proposições habituais ainda não tivessem um sentido irrepreensível [...] Por outro lado, parece claro que, onde há sentido, tem de haver uma ordem perfeita. - Logo, a ordem perfeita esconde-se também na mais vaga das proposições». ${ }^{10}$

O método descritivo que Wittgenstein adopta nas IF para expor trechos de fala, sintomas de perplexidades conceptuais a que tendenciosamente chamamos "problemas filosóficos" ou vias de esclarecimento gramatical para empregos indevidos de palavras ou de frases em jogos de linguagem, não tem o fito de corrigir nenhum modus linguístico, substituindo-o por outro, completamente analisado ou desambiguado.

Jede Kultur hat ihre eignen Möglichkeiten des Ausdrucks, die erscheinen, reifen, verwelken und nie wiederkehren».

${ }^{10}$ Wittgenstein, L. Philosophische Untersuchungen. Werkausgabe, Band 1, Frankfurt am Main, Suhrkamp, 1984, p. 295: «Einerseits ist klar, dass jeder Satz unserer Sprache "in Ordnung ist, wie er ist". D.h., dass wir nicht ein Ideal anstreben: Als hätten unsere gewöhnlichen, vagen Sätze noch keinen ganz untadelhaften Sinn [...]. - Anderseits scheint es klar: Wo Sinn ist, muss vollkommen Ordnung sein. Also muss die vollkommende Ordung auch im vagsten Satze stecken». 
Aqui parece que, ao falarmos de "método", estamos novamente a cruzar a duplicidade com que iniciámos esta exposição e que dizia respeito a uma confluência no entendimento de "álbum cultural" - diapositivo de sketches e infra-estrutura transcendental que confere unidade ao conjunto de questões investigadas.

O método descritivo é o reduto de "linguisticidade" de que os temas que as IF trabalham dispõem (Cavell fala em "wording the world" - uma expressão composta a roçar o intraduzível, mas plena de expressividade). A descrição do funcionamento das palavras é o princípio esquemático de síntese entre as formas orgânicas, mas não modelares, de matéria linguística e os nossos conceitos, ambos vinculados ao transcendental cultural (mesmo se ou sobretudo se esse vínculo está irreconhecível ou perdeu o seu ajuste gramatical). Mas não mudemos de autor.

\section{Jogos de linguagem numa linguagem comum}

No primeiro ponto do artigo de Cavell, "Everydayness as Home", o autor chama a atenção para uma subtileza no registo linguístico de Wittgenstein, entre o Tractatus e as Investigações. A saber: no primeiro, em 5.5563, o filósofo fala da linguagem "corrente" (natural) como "unserer Umgangssprache" (expressão traduzida por Pears e McGuinness para inglês como "our everyday language" e em outra versão de tradução por "our colloquial speech"); em contrapartida, em IF, §134, por exemplo, Wittgenstein utiliza a expressão "unserer alltäglichen Sprache" (traduzida por Anscombe como "our everyday language") 11 . Ao destacar esta peculiaridade na prosa wittgensteiniana, Cavell defende que a continuidade do pensamento de Wittgenstein a este respeito é assegurada por uma insistência, em ambas as expressões compostas em alemão, sobre unserer, ou seja, num possessivo integrante de duas coisas: uma comunidade de falantes competentes e uma linguagem partilhada ("nós", a "nossa linguagem").

Se tivéssemos de explorar as diferenças entre os dois adjectivos, aludiríamos ao carácter axial de Umgang, como algo que se circunda, que indicia um movimento "em torno" (uma tradução possível do alemão, ainda que descontextualizada, é "galeria"); por outro lado, alltäglich tem, naturalmente, a marca do diário, o registo do quotidiano e um aspecto de reiterabilidade e destreza numa prática recorrente (inclui mesmo o matiz de significado do que é "trivial").

$11 \mathrm{Na}$ tradução portuguesa de M.S. Lourenço, a primeira expressão (TLF, 5.563) foi traduzida por "linguagem corrente"; a do $\S 98$ das IF, por "linguagem de todos os dias". 
Uma tradução de Umgangssprache por "colloquial speech" pode indiciar uma conotação de "colloquial" com uma espécie de "descontracção estilística", como se as palavras da nossa linguagem natural não fossem mais do que "modas de fala", expressão de normas de sociabilidade em formas convencionais de veicular pensamentos e, portanto, susceptíveis ao crivo da análise filosófica, mas tomando esta como instrumento de precisão e esclarecimento - ou seja, como standard de "cientificidade" e, portanto, de "des-coloquialização".

Ora, a originalidade da abordagem de Cavell às IF é a de seguir a confiança que Wittgenstein deposita nas formas não estandardizadas de fala ${ }^{12}$, como "vias de esclarecimento" das supostas "perturbações profundas" da compreensão (vide IF§111). Estas perturbações seriam induzidas por uma errada interpretação das nossas formulações linguísticas habituais, o desrespeito pela verdadeira estrutura gramatical das quais thes conferiria a aparência de problemas com estatuto filosófico, quando na verdade são meras "fintas" à gramática.

Em IF §116, podemos ler a célebre "foto":

«Nós reconduzimos as palavras do seu emprego metafísico ao seu emprego quotidiano [alltägliche Verwendung]».

Antes de prosseguir, precisaremos de esclarecer a via de pensamento segundo a qual, para Wittgenstein, qualquer problema filosófico (ou antes: qualquer equívoco em termos de interpretação de significado que submete a uma investigação de tipo filosófico) tem uma proveniência linguística - bem como um âmbito de operatividade ou de resolução linguístico. E, dentro dessa via, um problema filosófico não é enfocado como uma disfunção da (nossa) linguagem ou de um jogo de linguagem. Com efeito, quer na tese do TLF supra-referida, quer em IF $\S 98$, Wittgenstein sublinha que qualquer frase em circulação na nossa linguagem corrente apresenta uma ordem lógica - ou uma adequação descritiva - não disputáveis.

Os problemas linguísticos (enquanto reduto de configuração dos problemas filosóficos) têm o seu eixo de rotação em compreensões desviantes do funcionamento da própria linguagem - e não em disfunções linguísticas.

A projecção de um falso modelo de correspondência entre formas de linguagem e estados de coisas (aqui corremos, nós também, o risco de justapor terminologias wittgensteinianas) impõe-nos uma visão errada da

12 É importante notar como aqui se fala de "speech" e não de "language", tal como em alemão, por exemplo em IF $\$ 335$, Wittgenstein fala de "Rede(weise)", ao invés de "Sprache". Em português, a expressão composta foi traduzida por "maneira de falar" (trad. cit.). 
forma como a linguagem atinge descritivamente a realidade. Esse missdeuten ("interpretar erradamente", "tomar uma coisa por outra"), como lhe chama Wittgenstein nas IF, é facilitado pelas formas como a linguagem "veste" o pensamento ou pela gramática de superfície dos nossos enunciados, que pode distorcer aquele vínculo semântico, uniformizando (e, por isso mesmo, falseando) as suas possibilidades interpretativas. Os jogos de linguagem, conforme concebidos e descontinuamente apresentados nas IF, nunca se constituem como enunciados de estados com coisas com um conteúdo proposicional definido e estável; a sua dinâmica interna comporta componentes linguísticas e não-linguísticas e a sua função é comunicar e não descrever. Atendendo a esse "missdeuten" é que, num parágrafo da segunda parte das IF, Wittgenstein insiste em que:

«A incontável diversidade de todos os jogos de linguagem quotidianos não nos chega à consciência porque a roupagem [Kleider] da nossa linguagem torna tudo igual» ${ }^{13}$.

O estatuto equívoco que, por causa deste "disfarce gramatical", uma frase pode adquirir num jogo de linguagem, deixa induzir uma falsa representação da realidade que assim está a ser referida. Para corrigir e remover esse erro vinculativo entre um conteúdo de pensamento e um conteúdo de realidade, o que a análise gramatical pode fazer é esclarecer (e não "reformar") os usos descontínuos da linguagem, através de um "nivelamento descritivo" das formas de expressão que são problemáticas - comparando estas com aquelas que não o são.

O esclarecimento dos diferentes tipos de uso linguístico é meramente analítico e não exige qualquer tipo de "cirurgia" ou reforma linguística na medida em que o seu principal fito é analisar formulações linguísticas problemáticas e não substituir formas de linguagem inespecíficas ou vagas por "fórmulas logicamente simples ou desambiguadas". A adequação que resulta da análise apenas restabelece a correspondência significativa entre o uso de uma expressão e o respectivo conteúdo de pensamento que, uma vez perdida, criou um problema linguístico que tem a aparência de um paradoxo com conteúdo filosófico.

13 «Die unsägliche Verschiedenheit aller der tagtäglichen Sprachspiele kommt uns nicht zum Bewusstsein, weil die Kleider unserer Sprache alles gleichmachen». Philosophische Untersuchungen, Teil II, Werkausgabe Band 1, Frankfurt am Main, Suhrkamp, 1984, p. 570. 


\section{O que é um "problema Wittgensteiniano"?}

A concepção do que seja um "problema filosófico" para Wittgenstein está muito próxima do seu entendimento do que pode ser um problema, tout court. Um problema é, prima facie, uma aporia com a qual devemos aprender algo, e não um mero obstáculo que pode ser evitado ou ultrapassado com astúcia ou com violência.

Em Vermischte Bemerkungen, num aforismo de 1946, podemos ler:

«A nova maneira de pensar é o que é difícil de estabelecer. Uma vez estabelecida [...] os velhos problemas desaparecem; na realidade, torna-se difícil retomá-los. Pois tinham assento na maneira como nos expressávamos e, se os vestirmos com uma nova forma de expressão, os velhos problemas são postos de parte, juntamente com as roupas velhas». ${ }^{14}$

Este esboço da formulação que um problema pode ter através de uma metáfora de vestuário é completamente transponível para a proposta wittgensteiniana do que é um "problema filosófico". O trabalho de análi$s e$ clarificadora dos termos de um problema filosófico, dada a indumentária linguística que o reveste, é mais determinante do que a sua resolução ou um desvio do seu âmbito gravitacional.

A razão de ser desta homologia pode encontrar-se, por um lado, na ideia de que em filosofia devemos estar preparados para pensar na extensão de um conceito e respectivas aplicações em jogos de linguagem heterogéneos, a partir de diferentes pontos de enfoque ou diferentes direcções, com repetidas passagens pelo mesmo lugar terminológico. É esse o objectivo da representação panorâmica: detectar a "semelhança" ou o ar de família [Familienähnlichkeit] entre palavras ou conteúdos proposicionais que, mesmo se não se podem inteiramente justapor, podem aproximar-se analiticamente, clarificando as suas afinidades ao lado das respectivas diferenças, ambas facultadas pelos contextos não linguísticos e pelas formas descontínuas de uso das expressões.

No fundo, Wittgenstein pensa que todas as questões filosóficas devem ser abordadas com base nesta ideia de análise, algo que se justifica à luz da sua afirmação de que os problemas filosóficos não provêm de nenhum elemento defectivo numa linguagem natural que devesse ser corrigida ou abandonada.

14 Wittgenstein, L. Vermischte Bemerkungen. Werkausgabe Band 8, Suhrkamp Verlag, Frankfurt am Main, 1977: «Es ist die neue Denkweise, die so schwer festzulegen ist. Ist die neue Denkweise festgelegt, so verschwinden die alten Probleme; ja, es wird schwer, sie wieder zu erfassen. Denn sie sitzen in der Ausdrucksweise; und wird eine neue angezogen, so streift man die alten Probleme mit dem alten Gewand ab». 
Pensemos: como pode uma dificuldade em se perceber a correlação entre a linguagem (qualquer linguagem, não enquanto "código", mas enquanto depositário de uma herança histórico-cultural, que é o património da própria Humanidade) e a realidade, uma correlação que é totalmente separada dos desejos e das intenções dos falantes (e a que, por isso, Wittgenstein chama metafisica), ter qualquer núcleo de resposta sediado num aspecto particular de um código linguístico? Tal não é (sequer) formalmente aceitável.

A contribuição wittgensteiniana para esclarecer essa configuração problemática passa por ver panoramicamente os nexos conectores, ou seja, as vias que ligam (e projectam o sentido de) linguagem, pensamento e realidade.

Se o que torna uma proposição verdadeira é a própria realidade (isto é, se nenhuma proposição é, em si mesma, verdadeira nem falsa), o que Wittgenstein nos diz é que há variadíssimas maneiras: 1) desse vínculo se estabelecer e 2) de o analisar em termos de condições de verdade ou, mais importante, de confirmar ou infirmar a sua asseverabilidade dentro de um jogo de linguagem.

A forma de olhar para um problema de filosofia é dar-lhe uma formulação linguística não problemática - desconstruir uma formulação obscura ou dúbia, devolvendo ao local de proveniência [Umgänglichkeit] as palavras que compõem essa formulação. Nada mais lógico: se foi no decurso de uma abstracção da nossa linguagem às circunstâncias práticas de fala que a aporia se constituiu (ao "olhar para a linguagem fora do jogo de linguagem"), então, ao devolvermos a formulação problemática à situação de que foi arrancada, o problema desaparece porque o seu enunciado linguístico volta a ser operante.

Sublinhámos antes que, para Wittgenstein, o âmbito de proveniência dos problemas filosóficos está sediado nos mal-entendidos quanto ao funcionamento da linguagem e não numa "disfunção" desta. O filósofo enumera várias formas possíveis desses mal-entendidos acontecerem: hábitos de isolar, por abstracção, conceitos ou fórmulas que preenchem uma função linguística da respectiva função; modelos para a análise gramatical de expressões cuja finalidade é simplificarem, reduzindo o número de interpretações que aquelas têm e que termina por deformar o seu significado; a assimilação de uma forma de linguagem a outra, com base num ideal de unidade das funções semânticas de ambas; a dissociação de conceitos ou funções que são próximos, aparentados ou mesmo complementares - por exemplo, linguagem e acção, uso e contexto, conhecimento e prática, mente e corpo, falar uma linguagem e dominar uma técnica, etc.

Cisões ou assimilações demasiado redutoras das funções da linguagem em diferentes formas discursivas ou diferentes estruturas sintácticas 
contribuem para distorcer a observação do seu modo de funcionamento e da forma como aquela "atinge" a realidade. Os dois tipos de tentação metafisica estão a montante de um erro na descrição da gramática de uma expressão, por um lado, e da identificação do verdadeiro estado de coisas a que a mesma remete.

Se assimilamos uma representação errada do que um dado cenário ou conjunto articulado de objectos é, cremos estar perante um "problema filosófico". Cavell fala nesse erro de atribuição, socorrendo-se do conceito - muito importante na economia das IF - de critério:

«Wittgenstein's idea of a criterion [...] is as if a pivot between the necessity of the relation among human beings Wittgenstein calls "agreement in forms of life" (\$241) and the necessity in the relation between grammar and the world that Wittgenstein characterizes as telling what kind of object anything is ( $\$ 373)$, where this telling expresses essence $(\S 375)$ and is accomplished by a process he calls "asking for our criteria". [...]» $\rangle^{15}$

Mas o que mais dificulta uma justa compreensão da maneira como a nossa linguagem funciona e, por isso mesmo, dos seus critérios, é que os prejuízos e incongruências quanto à correcção gramatical de algumas das suas formulações não se limitam a constituir uma rede de mal entendidos sobre formas particulares da linguagem, também contribuem a alterá-las. É o próprio ethos da linguagem, como produto de um transcendental cultural, que se adultera, como resultado da falência nas formas de interpretação daquela.

A herança cultural a que Wittgenstein se refere - e voltamos a pensar em Spengler e até na coetaneidade de ambos - é a sua própria, a da viragem numa época histórica que incubou uma crise do humano. Mas não façamos, nós também, "assimilações indevidas" (transposições gramaticais): uma "herança cultural" não é a Cultura entendida como um transcendental das formas de vida e das formas de linguagem - o transcendental não é afectado por um desgaste civilizacional.

Para não perder a conexão triangular que sublinhámos no início da abordagem ao artigo de Cavell - entre Cultura, Formas de Vida e Formas de Linguagem - e apelando à intuição forte de Wittgenstein de que o núcleo problemático está ao nível do terceiro ângulo, ou seja, nas Formas de Linguagem, devemos pensar que a "herança cultural" que Cavell refere a respeito de Wittgenstein constitui um reduto de tipo linguístico - nas mais variadas maneiras de entender formas de Linguagem -, o único que pode dar expressão a uma crise ou a um problema.

15 O.c., p. 334. 
A expressão wittgensteiniana "incompreensão da lógica da nossa linguagem" tem, pelo menos, uma dupla aplicação ao problema cultural cujos sintomas sob análise são linguísticos.

Por um lado, a génese desse problema cultural é um preconceito cujo âmbito é uma forma de vida determinada e que, no contexto dessa forma de vida, reúne forças e tendências que trabalham em conjunto com a forma de linguagem disponível, tornando um núcleo de expressões desta obsoleto ou descritivamente desajustado dos factos.

Por outro, as alterações em questão são conceptuais, numa primeira versão, mas têm repercussão na forma de vidja de que partem e terminam por erodir esta. Portanto, o que começa por ser uma incompreensão conceptual termina por ser um uso ilegítimo de conceitos - por causa das transições indevidas que já exemplificámos - e reflectir uma conversão na própria forma de linguagem.

Consequentemente, a crítica de tipo filosófico que era em primeira mão dirigida a incompreensões da lógica da nossa linguagem e a um núcleo de conceitos sob análise numa via de incompreensão, termina por afectar aquilo em que os nossos antigos conceitos se tornaram nos novos usos da linguagem. Mesmo nestes, a linguagem não tem um funcionamento indevido, mas passou a assumir funções que, pouco a pouco, divergem das anteriores. E, na medida em que a crítica filosófica estiver dirigida a uma linguagem e uma forma de cultura em transição, é a própria direcção seguida pelo processo de transição que está na base da crítica.

Neste ponto, essa análise, ao mesmo tempo que retém uma tipologia filosófica, perde paulatinamente a neutralidade com que Wittgenstein associava uma investigação de tipo filosófico; e isso termina por ter lugar, porque o que está sob análise, ao cabo de uma conversão no ethos da linguagem, é uma alteração conceptual e não apenas uma injusta compreensão de alguns conceitos.

Embora Wittgenstein tenha pensado que "a doença de uma época é curada por uma mudança na forma de vida dos seres humanos", o sentido do termo "doença" aqui, não parece, à luz do que vimos, ser linear. Aquilo que pode ser ponderado como uma "enfermidade" (mais do que propriamente uma "doença") é um problema conceptual identificado no decurso de uma investigação filosófica e cujo eixo de incidência é gramatical.

O que é difícil de "dissolver" [auflösen] neste ponto de "perda de orientação"16 para que a crítica conceptual nos remeteu, é a confusão

${ }^{16}$ Lembremos a famosa "receita" wittgensteiniana no Big Typescript, sobre a forma de um "problema filosófico": «Ein philosophische Problem ist immer von der Form: "Ich kenne mich einfach nicht aus"». In WITTGENSTEIN, L. Philosophical Occasions. Ed. James Klagge/ Alfred Nordmann, Oxford, Hackett Publishing Company, 1993, p. 180. 
disposicional em que a linguagem se encontra, não tendo mais os meios que lhe permitiam esclarecer um uso indevido. O que se passa é que as alterações conceptuais tornaram a nossa gramática inábil; não porque a tivessem forçado ou coagido as suas regras - isso não é concebível, para Wittgenstein.

A gramática que temos (que é arbitrária, mas descreve e regulamenta na linguagem as combinações possíveis de factos na realidade, não autorizando expressões sem sentido) é que não reconhece as vias das alterações conceptuais - porque essa não é uma competência sua - e não pode determinar nenhum sentido para expressões derivadas dessa conversão.

\section{O Transcendental do Álbum}

Em Crítica da Razão Pura, B25, numa passagem que se tornou célebre, Kant define com suficiente clareza a noção de transcendental:

«Chamo transcendental a todo o conhecimento que em geral se ocupa menos dos objectos do que do nosso modo de os conhecer, na medida em que este deve ser possível a priori». ${ }^{17}$

Formas hodiernas de manejar a noção de transcendental, que queiram fazer justiça à herança kantiana, sem se verem forçadas a seguir uma colagem estrutural aos seus propósitos, ou seja, atinentes a uma leitura essencialmente interpretativa e não meramente expositiva, ver-se-ão forçadas a ampliar a extensão daquela definição. Se não o fazem, ficam provavelmente limitadas quanto à possibilidade de defender uma "perspectiva transcendental" para uma abordagem a questões filosóficas cujo âmbito de proveniência e debate não seja o estritamente epistemológico.

Esse será também o nosso problema numa proposta de leitura das IF como um estudo de formas de linguagem, a partir da base de um "transcendental cultural". (Talvez devamos aqui sublinhar que, se ficássemos limitados à definição kantiana mais estrita de "transcendental", não estaríamos autorizados sequer a adjectivar essa noção).

Para Kant, se não ficamos limitados àquilo que nos é dado na experiência, é através de princípios que são nossos, ou seja, de princípios necessariamente subjectivos que, no entanto, constituem critérios de objectualidade. O dado (o material sensível que, formatado conceptualmente, constitui o âmbito da experiência) não pode fundar a operação na qual o ultrapassamos; só as estruturas subjectivas o podem fazer. Porém, não é suficiente que tenhamos essas estruturas - não menos importante é dispormos de ocasião para as exercitar. São os próprios dados da experiên-

17 Crítica da Razão Pura (KrV), Einleitung. B 25. 
cia que devem ser submetidos a princípios homólogos - a uma forma transcendental de "conhecer os objectos" - para serem compreendidos.

O material que se apresenta como correlato da constituição transcendental da subjectividade, como o âmbito do Mundo ou Natureza, deve necessariamente obedecer a princípios de enformação e inteligibilidade do mesmo tipo (mais ainda, aos mesmos princípios) que os que regulam o curso das nossas representações. Os mesmos princípios devem dar conta dos procedimentos subjectivos e ainda do facto de que o dado de constituição da experiência se submeta a estes procedimentos. É o requisito da "afinidade transcendental". Isto equivale a afirmar que a subjectividade não é de um tipo "empírico" ou "psicológico", mas sim "transcendental" e aquela afinidade é a consequência da unidade originariamente sintética da apercepção, como princípio de inteligibilidade e ordenação a priori dos fenómenos por um entendimento regulador e objectivante.

Ora, o que interessam estas notas num quadro estrito de definições para a (minha) tese que apresenta um "transcendental cultural" como critério de montagem topológica e de coordenação temática dos parágrafos das Investigações Filosóficas?

Cavell, no artigo citado, defende a ideia de que uma visão spengleriana da Cultura como uma forma de Natureza do humano está presente e é uma chave de leitura das IF. Se aceitarmos esta proposta, e com as salvaguardas que fizemos antes, ficamos habilitados a associar à perspectiva cultural um papel estruturador para o conjunto de parágrafos que constitui a obra de Wittgenstein (e a que mais do que um comentador chamou "uma selva de observações") como um eixo de conexão entre os diferentes aforismos, correspondente a uma "forma lógica".

A transposição da ideia de "forma lógica" para a segunda obra de Wittgenstein só pode ser aceite se a olharmos com a intenção de disponibilizar uma afinidade entre o enfoque do viajante - para aproveitar a metáfora do Prólogo - e o resultado fotográfico da viagem, o mesmo é dizer, entre o legado informativo e o princípio estruturador do mesmo.

Com a tolerância da analogia, temos um critério de unificação que não é apenas subjectivo, mas mostra a "afinidade transcendental" entre o álbum e as fotografias do álbum, cujo vínculo dispositivo é um esquema de projecção cultural, graças ao qual o objecto de que tratamos é uma obra de filosofia que revolveu o pensamento de uma época - tal como a Crítica da Razão Pura - e não uma memória de "esboços de longas e enredadas viagens" que se tenha limitado a saciar a curiosidade dos exploradores de lugares exóticos do pensamento.

Se aceitamos a chave interpretativa para a noção de transcendental, daquilo que diz Kant e do que diz Wittgenstein extraímos a nossa própria perspectiva de leitura. De KrV, A156/B195: 
«A possibilidade da experiência é, pois, o que confere realidade objectiva a todos os nossos conhecimentos a priori. Ora, a experiência assenta sobre a unidade sintética dos fenómenos, isto é, sobre uma síntese por conceitos do objecto dos fenómenos em geral, sem a qual nem sequer é conhecimento, apenas uma rapsódia de percepções que nunca caberiam todas num contexto, segundo as regras de uma consciência (possível) universalmente ligada, nem se incluiriam na unidade transcendental e necessária da apercepção. A experiência tem, pois, como fundamento, princípios da sua forma a priori, ou seja, regras gerais da unidade da síntese dos fenómenos; a realidade objectiva dessas regras, como condições necessárias, pode sempre ser mostrada na experiência e mesmo na possibilidade desta».

De IF, $\S 90$ :

«Para nós, é como se o nosso olhar tivesse que penetrar através dos fenómenos; mas a nossa investigação não se dirige para os fenómenos mas, poder-se-ia dizer, para a possibilidade dos fenómenos; quer dizer que tomamos consciência do género de enunciados que fazemos acerca dos fenómenos [...] Por isso as nossas são observações gramaticais». ${ }^{18}$

À parte das questões metodológicas de composição de mais de mil anotações filosóficas num livro, uma responsabilidade dividida por Wittgenstein e pelos herdeiros do seu Nachlass, o princípio de coerência que tentámos apor à dispersão dos temas e à forma indisciplinada da sua apresentação nas IF foi o de um critério de síntese, não tanto atinente aos objectos, como à "nossa forma de os conhecer" ou de discorrer sobre eles.

Deparámos com um "aditivo" a essa chave que, apenas assim descrita, tem todos os caracteres do transcendental à maneira kantiana, enriquecido com uma forma predicativa que é cultural. Portanto, nas IF a forma como se discorre sobre os fenómenos é cultural. Façamos como se o entendimento, a faculdade das regras e o reduto dos conceitos, que não faz nada sozinho, não representasse nada mais do que um puro princípio de enformação cultural dos fenómenos. $\mathrm{O}$ resto são as Investigações Filosóficas.

18 «Es ist uns, als müssten wir die Erscheinung durchschauen: unsere Untersuchung aber richtet sich nicht auf die Erscheinungen, sondern, wie man sagen könnte, auf die "Möglichkeiten" der Erscheinungen. Wir besinnen uns, heisst das, auf die Art der Aussagen, die wir über die Erscheinungen machen. [...] Unsere Betrachtung ist daher eine grammatische». In WITTGENSTEIN, L. Philosophische Untersuchungen, Frankfurt am Main, Werkausgabe Band 1, p. 292, 1984. 


\begin{abstract}
As it is well known, the Philosophical Investigations are formally structured as a set of paragraphs numerically sequenced (Part I), and a more arbitrary group of thematic remarks (Part II). In the Prologue and in a justifying way of putting it, Wittgenstein states that: "Thus this book is really only an Album». Taking it as an exhibition of a series of sketches, we can read (or see) the book as a collection of «pictures of thought». However, as I will argue, in a wider understanding of the Philosophical Investigations, the idea of an album has deeper implications than the methodological ones. With a somewhat spenglerian inspiration, the book follows a sort of cultural-transcendental perspective in accordance to the organic model of a philosophical approach to forms of life which have a primary linguistic configuration.
\end{abstract}

\title{
Referências Bibliográficas:
}

CAvell, S. "Declining Decline. Wittgenstein as a Philosopher of Culture". In The Cavell Reader, Oxford, Blackwell Publishers, 1996, 253-264.

Dilman, I. "von Wright on Wittgenstein: Philosophy and Culture". In Johannsessen, Kjell, Nordenstam, Tore (Eds.) Wittgenstein and the Philosophy of Culture. Proceedings of the 18th International Wittgenstein Symposium. Viena, Hölder-Pichler-Tempsky, 1996. 74-95.

GenOva, J. "A Map of The Philosophical Investigations". In Ludwig Wittgenstein. Critical Assessments. Vol. 2: From Philosophical Investigations to On Certainty: Wittgenstein's Later Philosophy. Routledge, 1996. 59-73.

KanT, I. Crítica da Razão Pura. Trad. de M.P.Santos e Alexandre F. Morujão. Lisboa, Fundação Calouste Gulbenkian, 1985.

VON WRIGHT, G.H. "Wittgenstein in relation to his times". In Portraits of Wittgenstein, Vol. 4. Bristol, Thoemmes Press, 1999.

WitTGENSTEIN, L. Philosophische Untersuchungen. Frankfurt am Main, Werkausgabe Band 1, 1989.

WitTGENSTEIN, L. Vermischte Bemerkungen. Edited by G.v Wright and Heikki Nyman. Oxford, Basil Blackwell, 1977. 